\title{
KONTRIBUSI IBU RUMAH TANGGA TERHADAP PENDAPATAN KELUARGA (Studi Kasus: Pengrajin Kerawang Di Desa Mongolato Kecamatan Telaga Kabupaten Gorontalo)
}

\author{
Sri Belawati Talipi \\ Benu Olfie Liesje Susana \\ Vicky R. B. Moniaga
}

\begin{abstract}
This study aims to identify what percentage contribution of housewives to family income, income Husband, and income Children. The research was conducted by Mongolato Village of Telaga District of Gorontalo.The research method was Purposive Sampling method, ie 40 (forty) respondents, Number of housewives working in kerawang workshop business group in Mogolato Village, Telaga District. Data collected in this research is data primary and secondary data with the method of data analysis using descriptive analysis. The results of research in Mongolato Village indicate that the contribution of housewife embankment income Kerawang to household income is sebersar 39.92\% of the total income of the whole family. And if seen from Age Household Contribution Most housewives are at productive age 36 until 40 Year that is equal to 66,40\%, whereas if seen from education level Household contribution is mostly found at level of elementary education that is $42,79 \%$, because level of education does not affect the creativity of the Housewife. And if seen from the number of dependents The contribution of the most housewives is in $\leq 1$ which is $40 \%$, because housewife who have children $\leq 1$ more spare time to do Sulam Krawang than housewife who has more dependents / children.
\end{abstract}

Keywords: contribution, housewife, family income, Mongolato Village, Telaga Sub-District, Gorontalo Regency.

\begin{abstract}
ABSTRAK
Penelitian ini bertujuan untuk mengidentifikasi berapa persentase kontribusi ibu rumah tangga terhadap pendapatan keluarga, pendapatan suami, dan pendapatan anak. Penelitian dilaksanakan Desa Mongolato Kecamatan Telaga Kabupaten Gorontalo. Metode penelitian menggunakan metode Purposive Sampling, yakni 40 (empat puluh) responden, Jumlah tenagakerja ibu rumah tangga pada kelompok usaha pembuatan kerajinan kerawang di Desa Mogolato, Kecamatan Telaga. Data yang dikumpulkan dalam penelitian ini adalah data primer dan data sekunder dengan Metode analisis data menggunakan analisis deskriptif. Hasil penelitian di Desa Mongolato menunjukakan bahwa Kontribusi pendapatan Ibu Rumah Tangga Penyulam Kerawang terhadap pendapatan rumah tangga yaitu sebersar $39.92 \%$ dari total pendapatan keseluruhan keluarga. Dan jika dilihat dari Umur Kontribusi Ibu Rumah Tangga terbanyak ada pada usia produktif 36 sampai 40 Tahun yaitu sebesar $66,40 \%$, sedangkan jika dilihat dari tingkat pendidikan Kontribusi Ibu Rumah Tangga terbanyak terdapat pada tingkat pendidikan SD yaitu 42,79\%, karena tingkat pendidikan tidak mempengaruhi kreativitas Ibu Rumah Tangga. Dan jika dilihat dari jumlah tanggungan Kontribusi Ibu Rumah Tangga terbanyak ada pada $\leq 1$ yaitu sebesar $40 \%$, karena Ibu Rumah Tangga yang memiliki anak $\leq 1$ lebih banyak waktu luang untuk melakukan Sulam Krawang daripada Ibu Rumah Tangga yang memiliki lebih banyak tanggungan / anak.
\end{abstract}

Kata kunci: kontribusi, ibu rumah tangga, pendapatan keluarga, Desa Mongolato, Kecamatan Telaga, Kabupaten Gorontalo. 


\section{PENDAHULUAN}

\section{Latar Belakang}

Pembangunan peran dan partisipasi seluruh masyarakat Indonesia tanpa memandang dari golongan manapun sangatlah dibutuhkan tidak terkecuali peran wanita yang sekarang ini sangat diakui oleh masyarakat. Penduduk wanita yang banyak sebagai sumberdaya manusia merupakan salah satu bagian dari modal dasar pembangunan bangsa. Jumlah perempuan yang demikian banyak merupakan aset dan problematika di bidang ketenagakerjaan. Keterlibatan wanita dalam kerja produktif akan menimbulkan perubahan sosial, dikarenakan salah satu wujud perubahan sosial adalah perubahan dalam kerja. Masuknya wanita lebih khusus ibu rumah tangga dalam pasar kerja atau kerja produktif berpengaruh terhadap kegiatan ekonomi rumah tangga, sehingga dapat terjadi perubahan struktur ekonomi keluarga (Wisadirana, 2004).

Ibu rumah tangga di Indonesia berupaya menutupi kekurangan kebutuhan keluarga disebabkan penghasilan suami kecil dan cenderung tidak menentu. Mereka juga terpaksa bekerja karena suami mendapat musibah, sakit, tertabrak, serta kecelakaan sehingga wanita yang menjadi kepala rumah tangga tidak punya pilihan. Ibu rumah itu haruslah bijak dalam mengatur belanja keluarga rumah tangga. Pengeluaran rutin sehari-hari yang merupakan kebutuhan pokok seperti makanan dan transport sekolah, haruslah diatur sedemikian rupa supaya tidak melebihi penghasilan wanita yang di dapat sehari-hari (Ari, dkk, 2000)

Kontribusi adalah keikutsertaan, keterlibatan, melibatkan diri maupun sumbangan. Dalam hal ini kontribusi tidak hanya berupa tindakan saja melainkan berupa materi. Dengan berkontribusi berarti individu berupaya untuk meningkatkan kehidupannya (Puspitasari, Puspitawati dan Herawati 2013). Berdasarkan aspek ekonomi keluarga, keterlibatan perempuan dalam ketenagakerjaan mempunyai arti tersendiri dalam kehidupan, baik sebagai individu, isteri, ibu rumah tangga maupun sebagai anggota masyarakat (Momuat, 2012).
Adanya keinginan seorang wanita bekerja untuk mencari nafkah dalam meningkatkan kontribusi pendapatan dalam memenuhi kebutuhan sehari-hari keluarganya. Dimana-mana wanita tergolong hanya aktif sebagai ibu rumah tangga yang mengurus suami, anak, maupun saudaranya akan tetapi fakta di lapangan justru wanita juga berperan aktif bekerja diluar rumah. Hal ini disebabkan karena rendahnya pendapatan suami dalam bekerja tentunya wanita juga berkontribusi membantu mencari nafkah agar kebutuhan keluarga terpenuhi (Puspitasari dkk, 2013).

Wanita cenderung sangat terampil dan teliti dalam bekerja seperti membuat kerajinan tangan. Sebab dilihat dari hasilnya tentu dapat memuaskan pihak konsumen yang membeli hasil kerajinan tangan yang dibuat oleh Ibu Rumah Tangga seperti dalam usaha kerajinan kerawang.

Kabupaten Gorontalo Kecamatan Telaga Desa Mongolato merupakan salah satu sentra industri kerajinan Sulam Krawang yang cukup di kenal di Indonesia. Dari hasil wawancara dengan responden, maka latar belakang Usaha kerajinan sulam Krawang di Desa Mongolato dimulai dari Tahun 1976 berawal dari usaha Rumah Tangga yang mencoba membuat sulaman krawang yang menghasilkan 3 lembar sapu tangan dan dijual Rp.175 / lembar dengan modal pokok Rp.125/ lembar. Berarti keluarga mendapatakan keuntungan Rp.50 / lembar yang menghasilakan Rp.150 sebagai keuntungan, hal inilah yang memberi motivasi keluarga untuk mengembangkan usaha sulam kerawang. Kemudian diikuti oleh rumah tangga / keluarga bahkan dilanjutkan dengan berbagai macam tipe / bentuk kemeja, dan baju wanita dalam rangka memenuhi permintaan dari konsumen maupun dari beberapa toko kerajinan di Kota Gorontalo. Dengan meningkatnya volume permintaan dari para konsumen maka pengrajin mulai menggembangkan usahanya dengan menerapkan berbagai hal seperti membuat aneka produkdengan dibantu Ibu Rumah Tangga yang terampil yang berada di desa tersebut. 
Dari produk yang telah dihasilkan maka dapat dilihat jumlah produksi dari setiap produk pada tahun 2013 yang dapat dilihat dari Tabel 1.

\begin{tabular}{|c|c|c|c|}
\hline Tabel & $\begin{array}{l}\text { 1. Jumlah } \\
\text { Kerawang } \\
\text { Mongolato }\end{array}$ & \begin{tabular}{lc}
\multicolumn{2}{c}{ Produksi } \\
g & di \\
o &
\end{tabular} & $\begin{array}{r}\text { Sulam } \\
\text { Desa }\end{array}$ \\
\hline No. & Jenis Produk & \multicolumn{2}{|c|}{ Jumlah } \\
\hline 1 & Jas & \multicolumn{2}{|c|}{324} \\
\hline 2 & Baju Wanita & \multicolumn{2}{|c|}{720} \\
\hline 3 & Kemeja & \multicolumn{2}{|c|}{1080} \\
\hline 4 & Kipas-kipas & \multicolumn{2}{|c|}{480} \\
\hline 5 & Sapu Tangan & \multicolumn{2}{|c|}{210} \\
\hline 6 & Alas Kemeja & \multicolumn{2}{|c|}{180} \\
\hline 7 & Jilbab & \multicolumn{2}{|c|}{504} \\
\hline 8 & Dasi & \multicolumn{2}{|c|}{270} \\
\hline 9 & Tas & \multicolumn{2}{|c|}{150} \\
\hline \multicolumn{2}{|c|}{ Jumlah } & \multicolumn{2}{|c|}{3918} \\
\hline
\end{tabular}

Sumber: Kantor Desa Mongolato

Pada Tabel 1 dapat dilihat jumlah produksi sulam kerawang di Desa Mongolato Kecamatan Telaga Kabupaten Gorontalo, dari produksi sulam krawang di atas maka peneliti tertarik untuk melihat usaha sulam krawang yang di lakukan oleh Ibu-ibu di Desa Mongolato dengan melihat berapa besar kontribusi ibu rumah tangga yang melakukan sulam krawang ini terhadap pendapatan keluarga.

\section{Perumusan Masalah}

Rumusan masalah dalam penelitian ini adalah berapa besar kontribusi ibu rumah tangga pengrajin kerawang terhadap pendapatan keluarga di Desa Mongolato Kecamatan Telaga?

\section{Tujuan Penelitian}

Tujuan dari penelitian ini adalah untuk mengidentifikasi berapa persentase kontribusi ibu rumah tangga terhadap pendapatan keluarga, pendapatan Suami, dan pendapatan Anak.

\section{Manfaat Penelitian}

Manfaat dari penelitian ini diharapkan berguna bagi peneliti dalam proses penyelesaian studi dan sebagai sumber informasi dan bahan referensi dalam penelitian-penelitian selanjutnya.

\section{METODOLOGI PENELITIAN}

\section{Lokasi dan Waktu Penelitian}

Penelitian ini dilaksanakan selama 6 (enam) bulan, mulai dari Bulan September 2017 sampai dengan Maret tahun 2018 yang dimulai dari persiapan sampai penyusunan laporan penelitian. Tempat penelitian adalah Desa Mongolato Kecamatan Telaga Kabupaten Gorontalo.

\section{Metode Pengambilan Sampel}

Sampeldalam penelitian ini adalah tenaga kerja ibu rumah tangga yang melakukan pekerjaan penyulaman krawang. Metode yang digunakan dalam penentuan sampel adalah metode Purposive Sampling, yakni 40 (empat puluh) responden, Jumlah tenaga kerja ibu rumah tangga pada tempat usaha pembuatan usaha kerajinan kerawang di Desa Mogolato, Kecamatan Telaga.

\section{Metode Pengumpulan Data}

Data yang dikumpulkan dalam penelitian ini adalah data primer dan data sekunder. Data primer diperoleh dari wawancara kepada tenaga kerja ibu rumah tangga di Desa Mongolato, Kecamatan Telaga, Kabupaten Gorontalo dengan menggunakan kuisioner, sedangkan data sekunder diperoleh dari instansi atau dinas terkait seperti Dinas Perindustrian dan Perdagangan Kabupaten Gorontalo, BPS (Badan Pusat Statistik) serta literatur-literatur yang berhubungan dengan penelitian ini.

\section{Konsepsi Pengukuran Variabel}

Adapun yang menjadi konsep pengukuran variabel dalam penelitian ini adalah sebagai berikut : 
1. Karakteristik Responden
a. Nama Responden
b. Umur
c. Pendidikan Terakhir
d. Jumlah Tanggungan
e. Jenis pekerjaan responden

2. Jenis Pekerjaan Suami

3. Jenis Pekerjaan Anak

4. Pendapatan dalam keluarga

a. Pendapatan isteri dalam usaha Sulam Kerawang (Rp/bulan)

b. Pendapatan suami (Rp/bulan)

c. Pendapatan anak yang sudah bekerja (Rp/bulan) / pendapatan lainnya

\section{Metode Analisis Data}

Metode analisis data yang digunakan dalam penelitian ini adalah menggunakan analisis deskriptif yaitu memberikan gambaran informasi dan mendeskripsikan peristiwa atau kejadian, perilaku orang atau keadaan pada tempat tertentu dan akan diinterpretasikan.

Dengan menganalisis data menggunakan rumus kontribusi :

$$
\text { Kontribusi IRT }=\frac{\text { Pendapatan IRT dari usaha kerawang }}{\text { Pendapatan Keluarga }} X 100 \%
$$

\section{Dimana :}

- Kontribusi Ibu Rumah Tangga dihitung berapa persentase dari semua pendapatan keluarga

- Pendapatan keluarga $=$ (Pendapatan suami + pendapatan isteri + pendapatan anak yang sudah bekerja)

Pendapatan Ibu Rumah Tangga yang bekerja sebagai penyulam krawang dihitung Rp. /bulan

\section{HASIL DAN PEMBAHASAN}

\section{Deskripsi Wilayah Penelitian}

Desa Mongolato adalah salah satu Desa di Kecamatan Telaga terletak di ketinggian $115 \mathrm{M}$ di atas permukaan laut dengan suhu rata-rata berkisar $27-28^{\circ} \mathrm{C}$ serta curah hujan rata-rata pertahun $195 \mathrm{~mm}$.
Desa Mongolato mempunyai batas wilayah yakni sebagai berikut :

Sebelah Utara : Desa Pantungo

Sebelah Timur : Desa Luhu

Sebelah Selatan : Desa Bunggalo, Desa Bulila

Sebelah Barat : Desa Bulota

Desa Mongolato memiliki luas wilayah 94,39 Ha dan secara administratif wilayah pemerintahan Desa Mongolato terdiri dari 4 (empat) Dusun yaitu : Dusun Dahlia, Dusun Motoluhu, Dusun Rumajaga, Dusun Ar Ridwan.

Jarak tempuh kepusat pemerintahan Kecamatan Telaga (Kantor camat) sekitar $1 \mathrm{Km}$ dan waktu tempuh 10 menit dengan menggunakan kendaraan bermotor, ke pusat pemerintahan Kabupaten sekitar $9 \mathrm{Km}$ dan waktu tempuh 30 menit dengan menggunakan kendaraan bermotor serta ke pemerintahan provinsi sekitar $15 \mathrm{Km}$ dengan waktu tempuh 60 menit dengan kendaraan bermotor.

\section{Keadaan Penduduk}

Penduduk merupakan sekumpulan manusia yang bearada didalam satu wilayah yang terikat oleh aturan-aturan dan saling berinteraksi satu sama lain secara terusmenerus.

Tabel 2. Jumlah Penduduk Menurut Jenis Kelamin

\begin{tabular}{llcc}
\hline No. & Jenis Kelamin & $\begin{array}{c}\text { Jumlah } \\
\text { (orang) }\end{array}$ & $\begin{array}{c}\text { Persentase } \\
(\boldsymbol{\%})\end{array}$ \\
\hline 1 & Laki-laki & 1387 & 49,32 \\
2 & Perempuan & 1425 & 50,68 \\
\hline Jumlah & $\mathbf{2 8 1 2}$ & $\mathbf{1 0 0}$ \\
\hline
\end{tabular}

Sumber: Kantor Desa Mongolato, 2017

Berdasarkan Tabel 2 dapat dijelaskan bahwa sebaran penduduk menurut jenis kelamin di Desa Mongolato terdapat 2.812 orang dimana jumlah laki-laki adalah 1.387 orang dan yang berjenis kelamin perempuan sebanyak 1.425 orang. Di Desa Mongolato jumlah penduduk perempuan lebih nanyak dari jumlah penduduk laki-laki.

\section{Penduduk Menurut Jenis Pekerjaan}

Jenis Pekerjaan merupakan pekerjaan yang menjadi pokok penghidupan (sumbu/pokok) pekerjaan / pencaharian utama yang dikerjakan untuk biaya sehari-hari. 
Adapun Tabel 3 yang menjelaskan penduduk menurut Jenis Pekerjaan di Desa Mongolato.

\begin{tabular}{llc}
\multicolumn{2}{c}{ Tabel 3. } & Jumlah Penduduk menurut Jenis \\
\multicolumn{2}{c}{ Pekerjaan di Desa } & Mongolato \\
\hline No. & Jenis Pekerjaan & Jumlah (orang) \\
\hline 1 & Pertanian & 37 \\
2 & Perdagangan & 93 \\
3 & Jasa & 142 \\
4 & PNS & 186 \\
5 & Industri & 14 \\
6 & Polri & 17 \\
7 & TNI & 2 \\
8 & Pensiunan & 60 \\
9 & Honorer & 45 \\
10 & Swasta & 15 \\
11 & Pertanian & 37 \\
\hline Jumlah & $\mathbf{2 8 1 2}$ \\
\hline
\end{tabular}

Sumber : Kantor Desa Mongolato, 2017

Pada Tabel 3 dapat dijelaskan bahwa jenis pekerjaan yang ada di Desa Mongolato dari jumlah penduduk 2812 memiliki jenis pekerjaan yang berbeda, jumlah jenis pekerjaan terbanyak yaitu 2.203 yang belum/tidak bekerja dimana terdiri dari bayi, anak-anak, anak yang bersekolah dan lansia, kemudian di ikuti oleh jenis pekerjaan PNS/ASN dengan jumlah 186 orang, 142 orang dengan jenis pekerjaan sebagai Jasa tenaga kerja yang didalamnya termasuk Jasa Tukang dan Jasa ojek bentor, 93 orang sebagai pedagang, 60 orang pensiunan, 45 orang honorer, 37 orang sebagai petani, 17 orang polri, 15 orang memiliki jenis pekerjaan swasta, 14 orang pada jenis pekerjaan industri dan terakhir yang memiliki jenis pekerjaan paling sedikit adalah 2 orang sebagai TNI.

Jika dilihat dari jenis pekerjaan di Desa Mongolato sudah bisa dibilang berhasil karena pekerjaan paling banyak adalah PNS/ASN.

\section{Deskripsi Umum Responden \\ Umur Responden}

Usia / Umur adalah lamanya waktu hidup yaitu terhitung sejak lahir sampai dengan sekarang. Penentuan usia dilakukan dengan menggunakan hitungan tahun Chaniago (2002). Menurut Simanjutak dalam Kumbadewi, dkk (2016) menyatakan bahwa apabila usia pekerja beranjak naik maka tingkat produktivitas dari pegawai tersebut akan meningkat karena pekerja tersebut berada dalam posisi usia produktif dan apabila usia pekerja menjelang tua maka tingkat produktivitas dari pegawai tersebut akan semakin menurunkarena keterbatasan faktor fisik dan kesehatan yang mempengaruhi.

Tabel 4. Persentase Ibu Rumah Tangga yang melakukan Sulam Kerawang Menurut Kelompok Umur

\begin{tabular}{lccc}
\hline No. & $\begin{array}{c}\text { Umum Responden } \\
\text { (Tahun) }\end{array}$ & $\begin{array}{c}\text { Jumlah } \\
\text { (orang) }\end{array}$ & $\begin{array}{c}\text { Persentase } \\
(\boldsymbol{\%})\end{array}$ \\
\hline 1 & $\leq 35$ & 2 & 5 \\
2 & $36-40$ & 27 & 67,5 \\
3 & $\geq 41$ & 11 & 27,5 \\
\hline Jumlah & & $\mathbf{4 0}$ & $\mathbf{1 0 0}$ \\
\hline
\end{tabular}

Sumber : Diolah dari Data Primer, 2018

Dari Tabel 4 dapat dijelaskan bahwa umur responden merupakan umur yang produktif karena jumlah responden terbanyak adalah dari umur 36 tahun sampai dengan 40 tahun sebangai sebanyak $67,5 \%$ responden. Dan Umur responde paling sedikit pada umur $\leq 35$.

\section{Pendidikan Responden}

Pendidikan merupakan usaha sadar dan terencana untuk mewujudkan suasana belajar dan proses pembelajaran agar peserta didik secara aktif mengembangkan potensi dirinya untuk memiliki kekuatan spiritual keagamaan, pengendalian diri, kepribadian, kecerdasan, akhlak mulia, serta keterampilan yang diperlukan dirinya, masyarakat, bangsa dan negara (UU No. 20 Tahun 2003).

Tabel 5. Jenis Pendidikan

\begin{tabular}{lccc}
\hline No. & $\begin{array}{c}\text { Pendidikan } \\
\text { Terakhir }\end{array}$ & $\begin{array}{c}\text { Jumlah } \\
\text { (orang) }\end{array}$ & $\begin{array}{c}\text { Persentase } \\
(\%)\end{array}$ \\
\hline 1 & SD & 17 & 42,5 \\
2 & SMP & 17 & 42,5 \\
3 & SMA & 6 & 15 \\
\hline Jumlah & & $\mathbf{4 0}$ & $\mathbf{1 0 0}$ \\
\hline
\end{tabular}

Sumber : Diolah dari Data Primer, 2018

Dari Tabel. 5 dapat dijelaskanJenis Pendidikan di Desa Mongolato yang memiliki jenis pendidikan SD sampai SMP lebih banyak jumlah responden $42,5 \%$, dan yang memiliki jenis pendidikan SMA atau dapat dibilang pendidikan paling tinggi memiliki jumlah responden yang paling sedikit. 


\section{Jumlah Tanggungan}

Jumlah tanggungan keluarga adalah banyaknya anggota keluarga yang terdiri dari anak serta orang lain yang turut serta dalam keluarga atau hidup dalam satu rumah dan makan bersama yang menjadi tanggung jawab kepala keluarga.

Tabel 6. Jumlah Tanggungan Responden

\begin{tabular}{lccc}
\hline No. & $\begin{array}{c}\text { Jumlah } \\
\text { Tanggungan }\end{array}$ & $\begin{array}{c}\text { Jumlah } \\
\text { (orang) }\end{array}$ & $\begin{array}{c}\text { Persentase } \\
(\%)\end{array}$ \\
\hline 1 & $\leq 1$ & 16 & 40 \\
2 & 2 & 13 & 32,5 \\
3 & $\geq 3$ & 11 & 27,5 \\
\hline Jumlah & & $\mathbf{4 0}$ & $\mathbf{1 0 0}$ \\
\hline
\end{tabular}

Sumber : Diolah dari Data Primer, 2018

Berdasarkan Tabel 6. dapat dilihat jumlah tanggungan responden yang memiliki jumlah responden terbanyak yaitu $\leq$ 1Tanggungan dengan persentase $40 \%$, diikuti jumlah tanggungan 2 orang yaitu 32,5\% dan terakhir yang memiliki jumlah responden paling sedikit yaitu $\geq 3$ Tanggungan dengan persentase $27,5 \%$.

\section{Pendapatan Responden}

Pendapatan merupakan sumber penghasilan seseorang yang memenuhi kebutuhan sehari-hari dan sangat penting artinya bagi kelangsungan hidup dan penghidupan seseorang secara langsung maupun tidak langsung (Suroto, 2000).

Tabel 7. Pendapatan Ibu Rumah Tangga

\begin{tabular}{lccc}
\hline No. & Pendapatan & Jumlah & $\begin{array}{c}\text { Persentase } \\
(\boldsymbol{\%})\end{array}$ \\
\hline 1 & $\leq 1.500 .000$ & 16 & 40 \\
2 & $1.500 .100-2.000 .000$ & 23 & 57,5 \\
3 & $\geq 2.000 .100$ & 1 & 2,5 \\
\hline Jumlah & & $\mathbf{4 0}$ & $\mathbf{1 0 0}$
\end{tabular}

Sumber : Diolah dari Data Primer, 2018

Berdasarkan Tabel 7. dapat dilihat pendapatan responden yang memiliki persentase terbanyak yaitu 1.500 .100 sampai 2.000.000 yaitu 57,5\%, diikuti 16 responden dengan pendapatan $\leq 1.500 .000$ yaitu $40 \%$, dan terakhir 1 responden memiliki pendapatan yaitu $\geq 2.000 .100$ yaitu $2,5 \%$.
Kontribusi Ibu Rumah Tangga

Kontribusi ibu rumah tangga yang dimaksud adalah menghitung berapa besar kontribusi yang diberikan ibu rumah tangga dalam pendapatan keluarga, dengan melihat pendapatan suami, pendapatan anak, dan pendapatan yang di dapat dalam usaha lainnya.

\section{Kontribusi Pendapatan Ibu Rumah Tangga Menurut Kelompok Umur}

Kontribusi Ibu Rumah Tangga menurut Umur yaitu untuk melihat berapa persentase pendapatan Ibu Rumah Tangga yang melakukan Sulam Krawang yang dilihat dari umur responden. Kontribusi Pendapatan Ibu Rumah Tangga Menurut Umur disajikan pada Tabel 8.

Tabel 8. Kontribusi Pendapatan Ibu Rumah Tangga Menurut Umur

\begin{tabular}{lcccc}
\hline No. & $\begin{array}{c}\text { Umur } \\
\text { (Tahun) }\end{array}$ & $\begin{array}{c}\text { Jumlah } \\
\text { Responden } \\
\text { (orang) }\end{array}$ & $\begin{array}{c}\text { Pendapatan } \\
\text { IRT (Rp) }\end{array}$ & $\begin{array}{c}\text { Persentase } \\
(\%)\end{array}$ \\
\hline 1 & $\leq 35$ & 2 & 3.300 .000 & 5,23 \\
2 & $36-40$ & 27 & 41.900 .000 & 66,40 \\
3 & $\geq 41$ & 11 & 17.900 .000 & 28,37 \\
\hline Jumlah & $\mathbf{4 0}$ & $\mathbf{6 3 . 1 0 0 . 0 0 0}$ & $\mathbf{1 0 0}$ \\
\hline \multicolumn{2}{l}{ Sumber : Diolah dari Data Primer } & 2018
\end{tabular}

Berdasarkan Tabel 8. dapat dilihat Persentase Pendapatan Ibu Rumah Tangga yang berumur $\leq 35$ Tahun dengan jumlah responden 2 orang dengan total pendapatan Rp.3.300.000 yaitu 5,23\%, dan Ibu Rumah Tangga yang berumur 36 - 40 Tahun dengan jumlah responden 27 orang dengan total pendapatan Rp.41.900.000 yaitu 66,40\%, sedangkan Ibu Rumah Tangga yang berumur $\geq 41$ Tahun dengan Jumlah responden 11 dengan total pendapatan Rp.17.900.000 yaitu 28,37\%. Maka Kontribusi Ibu Rumah Tangga tertinggi menurut kelompok umur terdapat pada usia produktif yaitu pada umur 36-40 Tahun.

\section{Kontribusi Pendapatan Ibu Rumah Tangga Menurut Tingkat Pendidikan}

Kontribusi Ibu Rumah Tangga menurut Tingkat Pendidikan yaitu untuk melihat berapa persentase Kontribusi Ibu Rumah Tangga yang melakukan Sulam Krawang yang dilihat dari Tingkat Pendidikan responden. Tabel Kontribusi Pendapatan Ibu Rumah Tangga Menurut Tingkat Pendidikan dapat dilihat pada tabel dibawah ini. 
Tabel 9. Kontribusi Pendapatan Ibu Rumah Tangga Menurut Tingkat Pendidikan

\begin{tabular}{|c|c|c|c|c|}
\hline No. & Pendidikan & $\begin{array}{c}\text { Jumlah } \\
\text { Responden } \\
\text { (orang) }\end{array}$ & $\begin{array}{l}\text { Pendapatan } \\
\text { IRT (Rp) }\end{array}$ & $\begin{array}{c}\text { Persentase } \\
(\%)\end{array}$ \\
\hline 1 & SD & 17 & 27.000 .000 & 42,79 \\
\hline 2 & SMP & 17 & 26.800 .000 & 42,48 \\
\hline 3 & SMA & 6 & 9.300 .000 & 14,73 \\
\hline \multicolumn{2}{|c|}{ Jumlah } & 40 & 63.100.000 & 100 \\
\hline
\end{tabular}

Berdasarkan Tabel 9. dapat dilihat persentase Ibu Rumah Tangga yang tingkat pendidikannya SD dengan jumlah responden 17 orang dengan total pendapatan Rp.27.000.000 yaitu 42,79\%, dan Ibu Rumah Tangga yang tingkat pendidikannya SMP dengan jumlah responden 17 orang dengan total pendapatan Rp.26.800.000 yaitu 42,48\%, sedangkan Ibu Rumah Tangga yang tingkat pendidikannya SMA denga jumlah responden 6 orang dengan total pendapatan Rp.9.300.000 yaitu $14,73 \%$. Maka Kontribusi Ibu Rumah Tangga tertinggi terdapat pada tingkat pendidikan SD, karena keterampilan dan kreatifitas ibu rumah tangga untuk menyulam kerawang tidak di ukur dari tingkat pendidikannya, keterampilan tersebut lahir secara turun temurun demi mempertahankan nilai budaya yang ada.

\section{Kontribusi Ibu Rumah Tangga Menurut Jumlah Tanggungan Keluarga}

Kontribusi Ibu Rumah Tangga menurut Jumlah Tanggungan Keluarga yaitu untuk melihat berapa persentase Pendapatan Ibu Rumah Tangga yang melakukan Sulam Krawang yang dilihat dari Jumlah Tanggungan Keluarga responden.

Tabel 10. Kontribusi Pendapatan Ibu Rumah Tangga menurut Tanggungan Keluarga

\begin{tabular}{lcccc}
\hline No. & $\begin{array}{c}\text { Tanggungan } \\
\text { Keluarga }\end{array}$ & $\begin{array}{c}\text { Jumlah } \\
\text { Responden } \\
\text { (orang) }\end{array}$ & $\begin{array}{c}\text { Pendapatan } \\
\text { IRT (Rp) }\end{array}$ & $\begin{array}{c}\text { Persentase } \\
(\boldsymbol{\%})\end{array}$ \\
\hline 1 & $\leq 1$ & 16 & 26.800 .000 & 42,47 \\
2 & 2 & 13 & 21.000 .000 & 33,28 \\
3 & $\geq 3$ & 11 & 15.300 .000 & 24,25 \\
\hline Jumlah & & $\mathbf{4 0}$ & $\mathbf{6 3 . 1 0 0 . 0 0 0}$ & $\mathbf{1 0 0}$ \\
\hline
\end{tabular}

Sumber : Diolah dari Data Primer, 2018

Berdasarkan Tabel 10. dapat dilihat persentase Ibu Rumah Tangga yang jumlah Tanggungannya $\leq 1$ dengan jumlah responden 16 orang dengan total Pendapatannya Rp.26.800.000 yaitu 42,47\%, dan Ibu Rumah Tangga yang jumlah Tanggungannya 2 dengan jumlah responden 13 orang dengan total pendapatan Rp.21.000.000 yaitu 33,28\%, sedangkan Ibu Rumah Tangga yang jumlah Tanggungannya $\geq 3$ dengan jumlah responden 11 orang dengan total pendapatan Rp.15.300.000 yaitu 24,25\%. Maka Kontribusi Ibu Rumah Tangga tertinggi terdapat pada Jumlah Tanggungan $\leq 1$, karena ibu rumah tangga yang punya tanggungan lebih sedikit sangat mudah untuk mengatur waktu sehingga waktu luang bisa diisi dengan melakukan penyulaman. Sedangkan ibu rumah tangga yang lebih banyak tanggungannya / mempunyai anak yang lebih banyak sulit menyisipkan waktu untuk menyulam. Hal tersebut bisa dicegah jika ada pihak yang dapat membantu, semua kendala tersebut hanya terletak pada masalah manajemen waktu.

\section{Kontribusi Pendapatan Ibu Rumah Tangga Menurut Jumlah Pendapatan}

Kontribusi Ibu Rumah Tangga menurut Jumlah Pendapatan yaitu untuk melihat berapa persentase Pendapatan Ibu Rumah Tangga yang melakukan Sulam Krawang yang dilihat dari Jumlah Pendapatan responden.

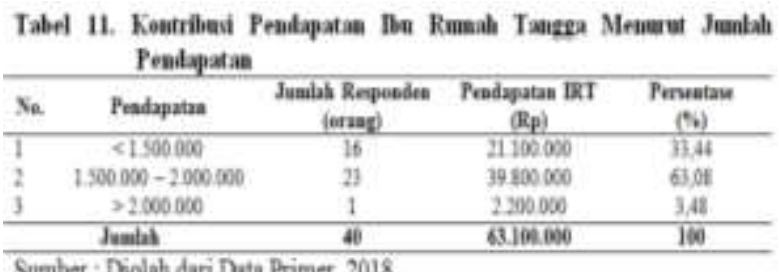

Berdasarkan Tabel 11. dapat dilihat persentase Ibu Rumah Tangga yang pedapatannya $\leq 1.500 .000$ dengan jumlah responden 16 orang dengan total Pendapatannya Rp.21.100.000 yaitu 33,44\%, dan Ibu Rumah Tangga yang Pendapatannya 1.500 .500 sampai 2.000.000 dengan jumlah responden 23 orang dengan total pendapatan Rp.39.800.000 yaitu $63,08 \%$, sedangkan Ibu Rumah Tangga yang Pendapatannya $\geq 2.000 .500$ dengan jumlah responden 1 orang dengan total pendapatan Rp.2.200.000 yaitu 3,48\%. Maka Kontribusi Ibu Rumah Tangga tertinggi terdapat pada tingkat Pendapatan 1.500.000 - 2.000.000. 
Kontribusi Pendapatan Ibu Rumah Tangga

Kontribusi Ibu Rumah Tangga di Desa Mongloato secara keseluruhan dari semua responden, dapat dilihat dari Tabel Tabulasi Pendapatan Keluarga pengrajin Sulam Krawang yaitu :

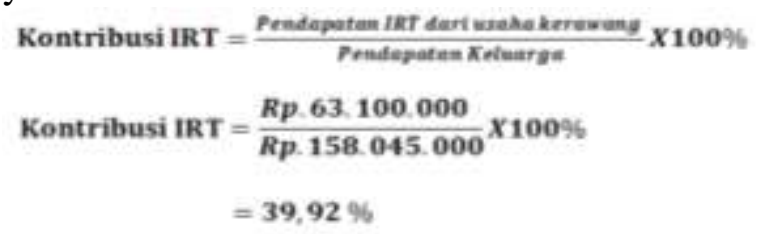

Berdasarkan data total pendaptan ibu rumah tangga pengrajin sulam kerawang dan pendapatan keluarga maka kontribusi pendapatan ibu rumah tangga terhadap pendapatan keluarga adalah 39,92 \%. Ini artinya kontribusi pendapatan ibu rumah tangga terhadap pendapatan keluarga baik, karena pendapatan yang di peroleh ibu rumah tangga yang bekerja sebagai penyulam sudah sangat membantu perekonomian keluarga dalam memenuhi dan mencukupkan kebutuhan dalam rumah tangga. Sehingga tanpa kontribusi ibu rumah tangga, maka kebutuhan dalam keluarga belum dapat tercukupi.

\section{KESIMPULAN DAN SARAN}

\section{Kesimpulan}

Dari hasil penelitian di Desa Mongolato menunjukakan bahwa Kontribusi pendapatan Ibu Rumah Tangga Penyulam Kerawang terhadap pendapatan rumah tangga yaitu sebesar $39.92 \%$ dari total pendapatan keseluruhan keluarga. Dan jika dilihat dari Umur Kontribusi Ibu Rumah Tangga terbanyak ada pada usia produktif 36 sampai 40 Tahun yaitu sebesar $66,40 \%$, sedangkan jika dilihat dari tingkat pendidikan Kontribusi Ibu Rumah Tangga terbanyak terdapat pada tingkat pendidikan SD yaitu $42,79 \%$, karena tingkat pendidikan tidak mempengaruhi kreativitas Ibu Rumah Tangga. Dan jika dilihat dari jumlah tanggungan Kontribusi Ibu Rumah Tangga terbanyak ada pada $\leq 1$ yaitu sebesar $40 \%$, karena Ibu Rumah Tangga yang memiliki anak $\leq 1$ lebih banyak waktu luang untuk melakukan Sulam Kerawang daripada Ibu Rumah Tangga yang memiliki lebih banyak tanggungan / anak.

\section{Saran}

Perlu adanya dukungan dari pemerintah Desa Mongolato untuk meningkatkan pendapatan para pengrajin krawang seperti lebih mempromosikan produk hasil kerajinan tanggan Krawang pemasaran lebih luas karena kerajinan Krawang adalah kerajinan turun temurun dari orang-orang terdahulu. Dan untuk para mengrajin agar tetap mempertahankan budaya Sulam Krawang tersebut kepada generasi muda.

\section{DAFTAR PUSTAKA}

Anonim. Undang-Undang RI Nomor 20 Tahun 2003 tentang Sistem Pendidikan Nasional. Jakarta.

Ari S, Chamsiah D, dan Dina L, Lilik S. 2000 Perempuan Yang Penuntun. Ashoka Indonesia. Bandung.

Chaniago Y. S. 2002. Kamus Lengkap Bahasa Indonesia. Pustaka Setia. Bandung

Kumbadewi, Suwendra, Susila. 2016. Pengaruh Umur, Pengalaman Kerja, Upah, Teknologi dan Lingkungan KerjaTerhadap Produktivitas Karyawan. Singaraja : Universitas Pendidikan Ganesha.

Momuat, S. 2012. Kontribusi Kerja Wanita Dalam Keluarga Petani Aren di Desa Rambunan dan Sawangan Sonder.Skripsi Fakultas Pertanian Universitas Sam Ratulangi Manado.

Puspitasari, N., Puspitawati, H., \& Herawati, T., 2013. Peran gender, Kontribusi ekonomi perempuan dan kesejahteraan keluarga petani holtikultura. Jurnal Ekologi Mansuia Vol. 6, No 1

Suroto. 2000. Strategi Pembangunan dan Perencanaan-perencanaan Kesempatan Kerja. Pustaka Sinar Harapan. Universitas Gajah Mada. Jakarta.

Wisadirana, Darsono. 2004. Sosiologi Pedesaan. Malang. UMM Press. 